\title{
Correction to: Reading for Realness: Porn Literacies, Digital Media, and Young People
}

\author{
Paul Byron ${ }^{1,3}$ (D) Alan McKee ${ }^{1} \cdot$ Ash Watson $^{2} \cdot$ Katerina Litsou $^{3} \cdot$ Roger Ingham $^{3}$
}

Published online: 26 December 2020

(C) The Author(s) 2020

\section{Correction to: Sexuality \& Culture https://doi.org/10.1007/s12119-020-09794-6}

The original version of this article unfortunately contained a mistake in affiliation information for authors Katerina Litsou and Roger Ingham.

Instead of "Katerina Litsou ${ }^{1} \cdot$ Roger Ingham ${ }^{1}$ ", they should be listed as "Katerina Litsou $^{3} \cdot$ Roger Ingham ${ }^{3 "}$.

The original article has been corrected.

Publisher's Note Springer Nature remains neutral with regard to jurisdictional claims in published maps and institutional affiliations.

The original article can be found online at https://doi.org/10.1007/s12119-020-09794-6.

Paul Byron

paul.byron@uts.edu.au

Roger Ingham

roger.ingham@soton.ac.uk

1 University of Technology Sydney (School of Communication), Sydney, NSW, Australia

2 UNSW (Social Policy Research Centre and Centre for Social Research in Health), Sydney, NSW, Australia

3 University of Southampton, University Road, Southampton SO17 1BJ, UK

记 Springer 